\title{
The medicolegal impact of misplaced pedicle and lateral mass screws on spine surgery in the United States
}

\author{
Eric W. Sankey, MD, ${ }^{1}$ Vikram A. Mehta, MD, MPH, ${ }^{1}$ Timothy Y. Wang, MD, ${ }^{1}$ Tracey T. Than, JD, ${ }^{2}$ \\ C. Rory Goodwin, MD, PhD, ${ }^{1}$ Isaac O. Karikari, MD, ${ }^{1}$ Christopher I. Shaffrey, MD, ${ }^{1}$ \\ Muhammad M. Abd-El-Barr, MD, PhD, ${ }^{1}$ and Khoi D. Than, MD'
}

1Department of Neurosurgery, Spine Division, Duke University Medical Center, Durham, North Carolina; and 2ProKarma Inc., Omaha, Nebraska

\begin{abstract}
Spine surgery has been disproportionately impacted by medical liability and malpractice litigation, with the majority of claims and payouts related to procedural error. One common area for the potential avoidance of malpractice claims and subsequent payouts involves misplaced pedicle and/or lateral mass instrumentation. However, the medicolegal impact of misplaced screws on spine surgery has not been directly reported in the literature. The authors of the current study aimed to describe this impact in the United States, as well as to suggest a potential method for mitigating the problem. This retrospective analysis of 68 closed medicolegal cases related to misplaced screws in spine surgery showed that neurosurgeons and orthopedic spine surgeons were equally named as the defendant ( $n=32$ and 31 , respectively), and cases were most commonly due to misplaced lumbar pedicle screws $(n=41,60.3 \%)$. Litigation resulted in average payouts of $\$ 1,204,422 \pm \$ 753,832$ between 1995 and 2019 , when adjusted for inflation. The median time to case closure was 56.3 (35.2-67.2) months when ruled in favor of the plaintiff (i.e., patient) compared to 61.5 (51.4-77.2) months for defendant (surgeon) verdicts $(p=0.117)$.
\end{abstract}

https://thejns.org/doi/abs/10.3171/2020.8.FOCUS20600

KEYWORDS defendant; intraoperative imaging; medical legal; misplaced; lawsuit; payout; pedicle screw; plaintiff; spine; medicolegal

$\mathrm{T}$ HE highly litigious environment within healthcare has resulted in a majority of physicians practicing defensive medicine, ${ }^{1-5}$ often leading to burnout ${ }^{6,7}$ and an exorbitant ethical and financial burden on medical and surgical care. ${ }^{7,8}$ In 2008, medical liability accounted for $\$ 55.6$ billion, representing $2.4 \%$ of the United States (US) healthcare expenditures that year, $, 5,7,10$ and the pervasive practice of defensive medicine may cost up to $\$ 210$ billion annually in the US. ${ }^{5} \mathrm{~A}$ similar trend has been observed in Europe. ${ }^{11}$

Neurosurgery is the specialty most frequently affected by lawsuits and the fear of litigation, both in the US and abroad, ${ }^{12}$ with spine surgery at the forefront. ${ }^{11,13-17}$ As a result, spine surgeons are nearly three times more likely than nonspine surgeons to practice defensive medicine, defined as the avoidance of high-risk procedures and the provision of unnecessary services and assessments beyond what is clinically necessary in an effort to avoid litagation. ${ }^{5}$ The average time to judgment in a case is approximately 5.1, 5.0 , and 3.4 years for defendant verdicts, plaintiff rulings, and settlements, respectively.,15 As a result, physicians spend an average of $11 \%$ of their careers dealing with one or more open malpractice claims. ${ }^{18}$ Neurosurgeons are especially impacted, spending an average of $27.2 \%$ of their careers in an open lawsuit. ${ }^{10}$

Studies have shown that the greatest proportion of malpractice claims in spine surgery are related to procedural error, ${ }^{10,11,14,16,17,19}$ often resulting in the highest payouts. ${ }^{11,20}$ For spine surgery, one common area for the potential avoidance of malpractice claims and subsequent payouts involves misplaced pedicle and/or lateral mass screws, which occurs in approximately $14 \%-55 \%$ of cases using standard techniques and results in neurological injury and/or durotomy in approximately $1 \%-8 \%$ of cases. ${ }^{21}$ Misplaced screws have the potential to cause severe and sometimes permanent neurological deficits, including spinal cord and/or nerve root injury, ${ }^{21}$ as well as to decrease the stability of the fusion construct, leading to delayed complications related to pseudarthrosis. Both issues represent the most frequent and highest payouts in spine malpractice claims. ${ }^{10,14,22}$ While 
several studies have explored many of the factors related to malpractice claims in spine surgery, the medicolegal impact of misplaced pedicle and/or lateral mass screws has not been directly reported in the literature. Thus, in the current study we aimed to describe this impact in the US, as well as to suggest a potential method for mitigating the problem.

\section{Methods \\ Verdict/Settlement Search and Inclusion/Exclusion Criteria}

A retrospective review of closed medicolegal cases with verdicts or settlements between 1995 and 2019 was performed using the Westlaw Edge legal research database (Thomson Reuters)., ${ }^{7,14,16,23,24}$ A search of closed federal and state malpractice claims within the Verdicts and Settlements section consisted of the following: "spine and surgery and pedicle and screw and fusion and (misplaced or misguided or mispositioned) and surgeon." Inclusion criteria consisted of malpractice claims against surgeons for complications related to misplaced pedicle and/or lateral mass screws. Cases involving wrong-level or -side surgery, implant malfunction, or other misplaced spinal instrumentation (e.g., interbody cases, rods, surgical instruments, etc.) were excluded from analysis.

\section{Case Information}

Lawsuit information regarding the plaintiff's age at the time of the malpractice claim, sex, postoperative complaint, indication for index surgery, defendant surgeon specialty (neurosurgery vs orthopedics), and delayed diagnosis or treatment, as well as case location by state and case year, was obtained. States were then grouped by US region and case year by 5 -year intervals. Operative information including fusion level, number of levels fused, level of misplaced screw(s), single versus multiple misplaced screw(s), presence of known CSF leakage, and primary injury due to screw misplacement was also collected. Judgment information associated with a defendant (surgeon) versus plaintiff (patient) ruling, trial versus settlement versus arbitration decision, award amount, and time to decision or case closure from index surgery was also recorded. Plaintiff award amounts were adjusted for inflation as of April 2020 using an online inflation calculator provided by the US Bureau of Labor Statistics (https://www.bls.gov/ data/inflation_calculator.htm).

\section{Statistical Analysis}

GraphPad Prism version 6.01 for Windows was used for all descriptive analyses (GraphPad Software). Categorical and continuous data are described as frequency (percentage) and median (interquartile range), respectively, except for the use of mean \pm standard deviation for award amounts since both nominal and inflation-adjusted award totals passed (alpha $=0.05$ ) the D'Agostino-Pearson omnibus normality test. Fisher's exact test and the Mann-Whitney U-test were used for the analysis of categorical and continuous data, respectively, except when an unpaired t-test was utilized for analyses related to normalized, nominal, and inflation-adjusted award totals. A p $<0.05$ was considered statistically significant.

\section{Results}

The initial search using the terms above returned 3654 cases. Each case was then carefully screened for relevance and sufficient data. After the removal of duplicates, a total of 68 unique cases met our inclusion criteria and were included for analysis.

\section{Plaintiff and Case Demographics}

All case demographics are summarized in Table 1. A total of $47(69.1 \%)$ cases resulted in a decision for the defendant and 21 (30.9\%) for the plaintiff. Among the plaintiff-awarded cases, 13 (61.9\%) were decided by jury trial, $7(33.3 \%)$ by settlement, and $1(4.8 \%)$ by arbitration. The median time to case closure was longer for defendantawarded cases, but this finding was not statistically significant (61.5 vs 56.3 months, $\mathrm{p}>0.05$ ). Neurosurgeons and orthopedic surgeons were named as the defendant in an equal number of cases, and the decision for the plaintiff versus the defendant was also similar between specialties. The majority of plaintiffs were male $(\mathrm{n}=44,64.7 \%)$, and the median age among all cases was 46 years (range $37-57$ years). The states with the most cases included California $(\mathrm{n}=10,14.7 \%)$, New York $(\mathrm{n}=6,8.8 \%)$, Pennsylvania $(\mathrm{n}=$ $6,8.8 \%)$, and Illinois ( $\mathrm{n}=5,7.3 \%$; Table 2). When grouped by US region, most cases occurred in the Northeast $(\mathrm{n}=$ $25,36.8 \%)$, followed by the West $(n=15,22.1 \%$; Fig. 1$)$. Ultimately, no significant differences in case demographics were found between plaintiff and defendant judgments (Table 1).

\section{Plaintiff Claim and Index Surgery Information}

Back pain/spinal stenosis and neurogenic claudication/ radiculopathy were the most frequently reported indications for the index surgery, accounting for $13(19.1 \%)$ and $11(16.2 \%)$ cases, respectively. The most frequent primary injury listed for a lawsuit was nerve root injury, present in $81.0 \%(n=17)$ and $74.5 \%(n=35)$ of plaintiff- and defendant-awarded cases, respectively $(\mathrm{p}=0.7)$. This was followed by pseudarthrosis requiring revision surgery, present in $14.3 \%(\mathrm{n}=3)$ and $14.9 \%(\mathrm{n}=7)$ of plaintiffand defendant-awarded cases, respectively $(\mathrm{p}=0.99)$. The largest inflation-adjusted payout awarded to the plaintiff $(\$ 3,372,185)$ for nerve root injury occurred in a 36-yearold male who had undergone an L4-S1 posterior spinal fusion, which resulted in permanent and direct injury to right L5 and S1 nerve roots, with foot drop and radiculopathy. Similarly, the highest inflation-adjusted amount awarded $(\$ 2,302,472)$ for pseudarthrosis was attributed to a medially breached pedicle screw during an L5-S1 fusion that was determined to have caused the failed union and subsequent need for revision surgery. The majority of screws were misplaced in the lumbar spine for both plaintiff- and defendant-awarded cases $(66.7 \%$ vs $57.4 \%$, respectively, $\mathrm{p}$ $=0.564$; Table 1). Examples of both laterally and medially misplaced lumbar pedicle screws are provided in Fig. 2.

Of note, while only $38.2 \%(n=26)$ of cases in our study mentioned the use of intraoperative radiographic confirmation, only one of these cases reported that the misplaced screw had been caught prior to leaving the operating room, which had resulted in an inadvertent dural tear and 
TABLE 1. Characteristics of medicolegal cases related to misplaced screws in spine surgery

\begin{tabular}{|c|c|c|c|}
\hline Characteristic & $\begin{array}{l}\text { Plaintiff } \\
\text { Awarded }\end{array}$ & $\begin{array}{l}\text { Defendant } \\
\text { Awarded }\end{array}$ & p Value \\
\hline No. of cases & 21 & 47 & \\
\hline Median plaintiff age in yrs (IQR) & $46(38-52)$ & $46(37-57)$ & 0.976 \\
\hline Plaintiff sex, no. (\%) & & & 0.99 \\
\hline Male & $14(66.7)$ & $30(63.8)$ & \\
\hline Female & $7(33.3)$ & $17(36.2)$ & \\
\hline Surgeon specialty, no. (\%) & & & 0.99 \\
\hline Neurosurgery & $9(42.9)$ & $22(46.8)$ & \\
\hline Orthopedics & $9(42.9)$ & $21(44.7)$ & \\
\hline Both & $1(4.8)$ & $0(0)$ & \\
\hline Unknown & $2(9.5)$ & $4(8.5)$ & \\
\hline Index surgery category, no. (\%) & & & 0.817 \\
\hline Back pain/spinal stenosis & $3(14.3)$ & $10(21.3)$ & \\
\hline $\begin{array}{l}\text { Neurogenic claudication/ } \\
\text { radiculopathy }\end{array}$ & $2(9.5)$ & $9(19.1)$ & \\
\hline Deformity/spondylolisthesis & $2(9.5)$ & $4(8.5)$ & \\
\hline Herniated disc(s) & $2(9.5)$ & $4(8.5)$ & \\
\hline Trauma & $2(9.5)$ & $2(4.3)$ & \\
\hline Unknown & $10(47.6)$ & $18(38.3)$ & \\
\hline Involved pedicle region(s), no. (\%) & & & 0.564 \\
\hline Cervical & $1(4.8)$ & $7(14.9)$ & \\
\hline Thoracic & $1(4.8)$ & $3(6.4)$ & \\
\hline Lumbar & $14(66.7)$ & $27(57.4)$ & \\
\hline Sacral & $2(9.5)$ & $3(6.4)$ & \\
\hline Multiple & $1(4.8)$ & $2(4.3)$ & \\
\hline Unknown & $2(9.5)$ & $5(10.6)$ & \\
\hline Single- vs multilevel fusion, no. (\%) & & & 0.757 \\
\hline Single & $7(33.3)$ & $19(40.4)$ & \\
\hline Multiple & $8(38.1)$ & $15(31.9)$ & \\
\hline Unknown & $6(28.6)$ & $13(27.7)$ & \\
\hline Median no. of levels fused (IQR) & $2(1-2)$ & $1(1-2)$ & 0.675 \\
\hline $\begin{array}{l}\text { Single vs multiple misplaced } \\
\text { screw(s), no. (\%) }\end{array}$ & & & 0.73 \\
\hline Single & $12(57.1)$ & $31(66.0)$ & \\
\hline Multiple & $4(19.0)$ & $8(17.0)$ & \\
\hline Unknown & $5(23.8)$ & $8(17.0)$ & \\
\hline Primary injury category, no. (\%) & & & 0.753 \\
\hline Spinal cord injury & $0(0)$ & $1(2.1)$ & \\
\hline Nerve root injury & $17(81.0)$ & $35(74.5)$ & \\
\hline Vascular injury & $1(4.8)$ & $1(2.1)$ & \\
\hline $\begin{array}{l}\text { Dural tear requiring revision } \\
\text { surgery }\end{array}$ & $0(0)$ & $1(2.1)$ & \\
\hline $\begin{array}{l}\text { Facet damage requiring revision } \\
\text { surgery }\end{array}$ & $0(0)$ & $2(4.3)$ & \\
\hline $\begin{array}{l}\text { Pseudarthrosis requiring } \\
\text { revision surgery }\end{array}$ & $3(14.3)$ & $7(14.9)$ & \\
\hline Known CSF leak, no. (\%) & $2(9.5)$ & $4(8.5)$ & 0.99 \\
\hline Delayed diagnosis, no. (\%) & $6(28.6)$ & $21(44.7)$ & 0.176 \\
\hline Delayed treatment, no. (\%) & $7(33.3)$ & $25(53.2)$ & 0.101 \\
\hline
\end{tabular}

TABLE 2. Cases by US region and state

\begin{tabular}{|c|c|c|c|}
\hline $\begin{array}{c}\text { US } \\
\text { Region/State }\end{array}$ & $\begin{array}{l}\text { Plaintiff } \\
\text { Awarded }\end{array}$ & $\begin{array}{l}\text { Defendant } \\
\text { Awarded }\end{array}$ & $\mathrm{p}$ Value \\
\hline No. of cases & 21 & 47 & \\
\hline West, no. (\%) & $8(38.1)$ & $7(14.9)$ & 0.055 \\
\hline California & $5(23.8)$ & $5(10.6)$ & \\
\hline Colorado & $2(9.5)$ & $1(2.1)$ & \\
\hline Oregon & $0(0)$ & $1(2.1)$ & \\
\hline Washington & $1(4.8)$ & $0(0)$ & \\
\hline Midwest, no. (\%) & $3(14.3)$ & $10(21.3)$ & 0.74 \\
\hline Illinois & $2(9.5)$ & $3(6.4)$ & \\
\hline Minnesota & $0(0)$ & $1(2.1)$ & \\
\hline South Dakota & $0(0)$ & $1(2.1)$ & \\
\hline Kansas & $0(0)$ & $1(2.1)$ & \\
\hline Michigan & $0(0)$ & $4(8.5)$ & \\
\hline Missouri & $1(4.8)$ & $0(0)$ & \\
\hline Southwest, no.(\%) & $1(4.8)$ & $6(12.8)$ & 0.423 \\
\hline Texas & $1(4.8)$ & $3(6.4)$ & \\
\hline Arizona & $0(0)$ & $1(2.1)$ & \\
\hline Oklahoma & $0(0)$ & $1(2.1)$ & \\
\hline New Mexico & $0(0)$ & $1(2.1)$ & \\
\hline Southeast, no. (\%) & $2(9.5)$ & $6(12.8)$ & 0.99 \\
\hline Arkansas & $1(4.8)$ & $1(2.1)$ & \\
\hline Virginia & $1(4.8)$ & $1(2.1)$ & \\
\hline Tennessee & $0(0)$ & $1(2.1)$ & \\
\hline Kentucky & $0(0)$ & $1(2.1)$ & \\
\hline Florida & $0(0)$ & $2(4.3)$ & \\
\hline Northeast, no. (\%) & $7(33.3)$ & $18(38.3)$ & 0.789 \\
\hline Connecticut & $2(9.5)$ & $1(2.1)$ & \\
\hline Pennsylvania & $2(9.5)$ & $4(8.5)$ & \\
\hline New York & $1(4.8)$ & $5(10.6)$ & \\
\hline New Jersey & $2(9.5)$ & $2(4.3)$ & \\
\hline Massachusetts & $0(0)$ & $4(8.5)$ & \\
\hline Maryland & $0(0)$ & $2(4.3)$ & \\
\hline
\end{tabular}

L5 nerve root injury. In this example, the surgeon replaced the misplaced screw prior to leaving the operating room, which arguably played a significant role in the jury ruling in favor of the defendant (surgeon). Moreover, several cases stated that the surgeon used only the anteroposterior or the lateral view, but not both, and the plaintiff's counsel used this information in support of their claim. Also notable, only one claim reported the use of intraoperative CT and was ultimately ruled in favor of the defendant.

\section{Plaintiff Payout Information}

Nominal and inflation-adjusted award payouts were higher for trial verdicts than for settlement/arbitration, with a nominal average of $\$ 1,140,473 \pm \$ 841,683$ versus $\$ 788,533 \pm \$ 306,186$ awarded to the plaintiff, respectively $(\mathrm{p}=0.30)$. When adjusted for inflation, these values increased to $\$ 1,330,201 \pm \$ 882,023$ versus $\$ 970,832$ $\pm \$ 381,619$, respectively $(p=0.32$; Fig. 3$)$. The amount 


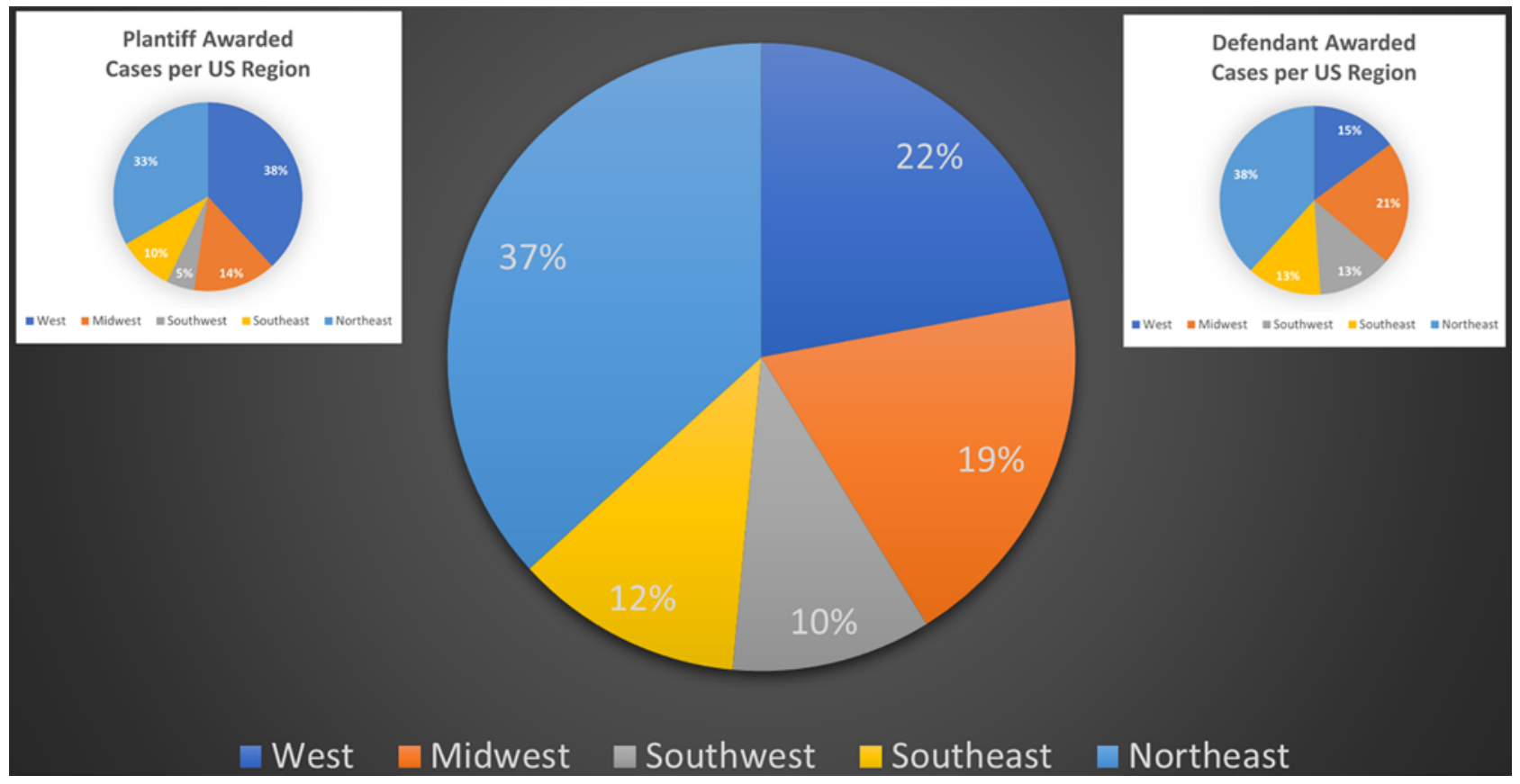

FIG. 1. Percentage of cases per US region (center). Plaintiff-awarded cases by US region (left). Defendant-awarded cases by US region (right).

awarded was not significantly different across US regions ( $\mathrm{p}=0.9$; Fig. 4). As compared to cases in 1995-2009, those in 2010-2019 resulted in a significantly higher average nominal payout to plaintiffs $(\$ 776,439 \pm \$ 74,460$ vs $\$ 1,506,000 \pm \$ 385,527, p=0.028)$. However, this difference was no longer significant when adjusted for inflation $(\$ 1,016,000 \pm \$ 90,875$ vs $\$ 1,630,000 \pm \$ 422,405$, p $=0.09)$. Ultimately, no significant differences were seen in inflation-adjusted award information between plaintiff and defendant (Table 3).

\section{Discussion}

\section{Impact of Medical Malpractice on Neurosurgeon and Orthopedic Surgeon Careers}

Medical malpractice litigation has made a significant impact on spine surgery, with many spine surgeons avoid-
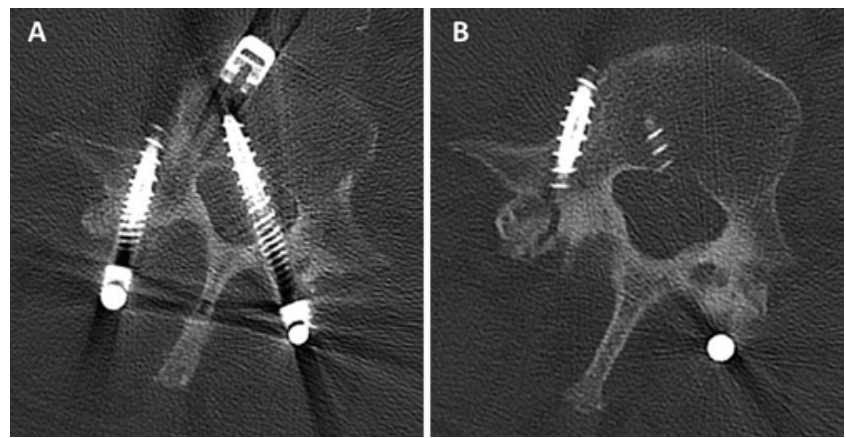

FIG. 2. Axial lumbar CT scans demonstrating both laterally (right) and medially (left) misplaced pedicle screws, resulting in pedicle and transverse process fractures $(\mathbf{A})$ and canal compromise (A and $\mathbf{B})$. ing complex cases or practicing other defensive medicine tactics in an effort to avoid being sued. ${ }^{5}$ Moreover, the majority of neurosurgeons spend more than $10 \%$ of their annual revenue on malpractice insurance, ${ }^{1,14}$ and the excessive financial risk of litigation is even leading some insurers to no longer offer coverage to spine surgeons..$^{19} \mathrm{~A}$ 2011 study in the New England Journal of Medicine found that $19.1 \%$ of neurosurgeons are named as a defendant in a malpractice suit each year (highest of any specialty). ${ }^{12}$ Moreover, $88 \%$ of physicians in high-risk specialties, like neurosurgery, are involved in a lawsuit by age 45 , increasing to a concerning $99 \%$ by 65 years of age..$^{12}$ Such litigation places a substantial financial, temporal, and emotional burden on physicians in high-risk specialties, with studies showing that up to $72 \%$ of neurosurgeons ${ }^{1}$ admitted that their fear of litigation significantly influenced their practice, ${ }^{25}$ with many avoiding high-risk patients altogether. ${ }^{1}$ Similarly, Nahed et al. reported that $69.3 \%$ of neurosurgeons who responded to their survey saw "every patient as a potential lawsuit."1

Additional survey data have shown that $50 \%$ of physicians exhibit at least a temporary loss of self-esteem after a malpractice claim, and at least $25 \%$ experience depression. ${ }^{22}$ As stated above, the average neurosurgeon spends $27.2 \%$ of his or her entire career in an open malpractice claim,,$^{10}$ and each case can take an average of 5.1, 5.0, and 3.4 years for defendant verdicts, plaintiff rulings, and settlements, respectively. ${ }^{7,15}$ Likewise, neurosurgeons have a higher risk than practitioners in other specialties of being named in multiple malpractice suits given the particularly high-risk nature of the specialty. ${ }^{10}$ Even when found in favor of the defendant (surgeon), each case ultimately takes a substantial emotional and financial toll on the physician(s) involved. 


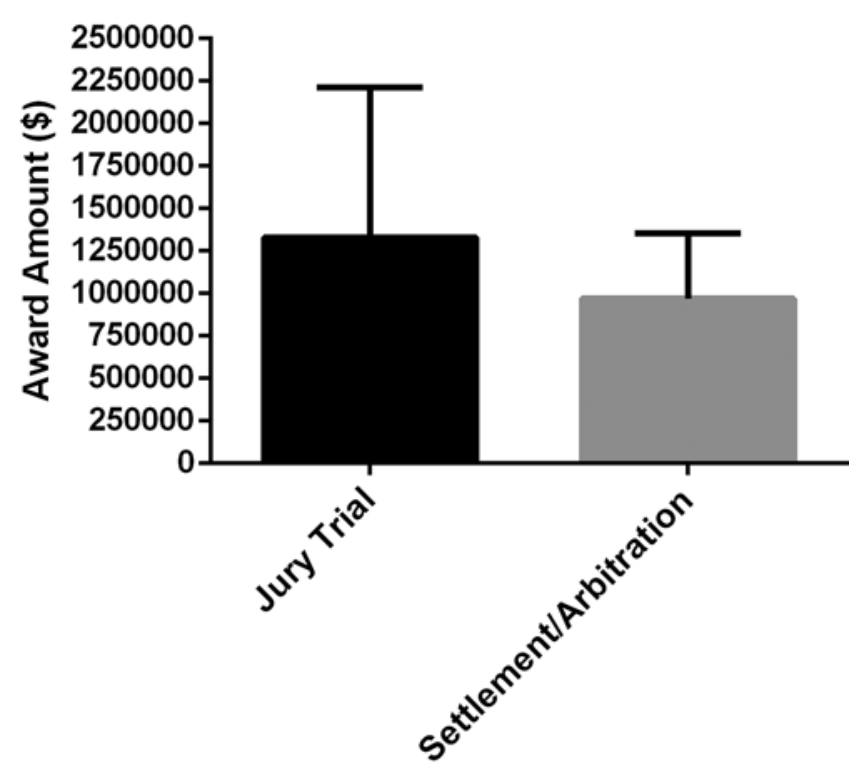

FIG. 3. Mean amounts awarded \pm SD to plaintiffs by jury trial $(n=13)$ versus settlement/arbitration $(n=7)$, adjusted for inflation as of April 2020. Of note, the award amount for one settlement case was undisclosed. \$ = US\$.

While the majority of claims are found to lack merit, resulting in a verdict in favor of the defendant or case dismissal,, $13-16$ at least $37 \%$ are considered valid. ${ }^{26}$ Regardless, payouts to plaintiffs are often substantial, averaging in the hundreds of thousands to millions of dollars in both the US and Europe. ${ }^{10,11,14,17,20}$ Communication of errors and expectations, thorough documentation, and selection of appropriate patients and surgical indications have been shown to reduce the likelihood of a successful malpractice claim. ${ }^{13,16,27,28}$ In addition, attempts at tort reform in some states have helped limit the financial burden of medical malpractice payouts through methods such as capitation. ${ }^{16,20,22,26}$ However, efforts to limit malpractice claims in the first place are greatly needed.

\section{Financial Burden of Medical Malpractice Claims Related to Misplaced Pedicle and/or Lateral Mass Screws}

Several studies have shown that spine surgery is at the highest risk for litigation among the surgical subspecialties. ${ }^{12,29}$ The majority of claims are related to technical and procedural errors, ${ }^{29}$ including misplaced pedicle and/ or lateral mass screws. Procedural errors led to combined payouts totaling $\$ 124,943,933$ in neurosurgery claims between 2003 and 2012 in a study looking at data from the Physician Insurers Association of America Data Sharing Project. ${ }^{10}$ However, our study is the first to report the direct medicolegal impact of screw misplacement on US spine surgery, with $30.9 \%$ of judgments/settlements in favor of the plaintiff, resulting in average payouts of $\$ 1,204,422$ $\pm \$ 753,832$ per claim. Similar to our findings, prior studies have shown that settlements result in lower payouts than cases that are ultimately taken to trial, $7,14,15,30$ with awards ranging from $\$ 125,000$ to $\$ 9,000,000$ compared to $\$ 134,000$ to more than $\$ 38,000,000$. $^{7,15}$ Nevertheless,

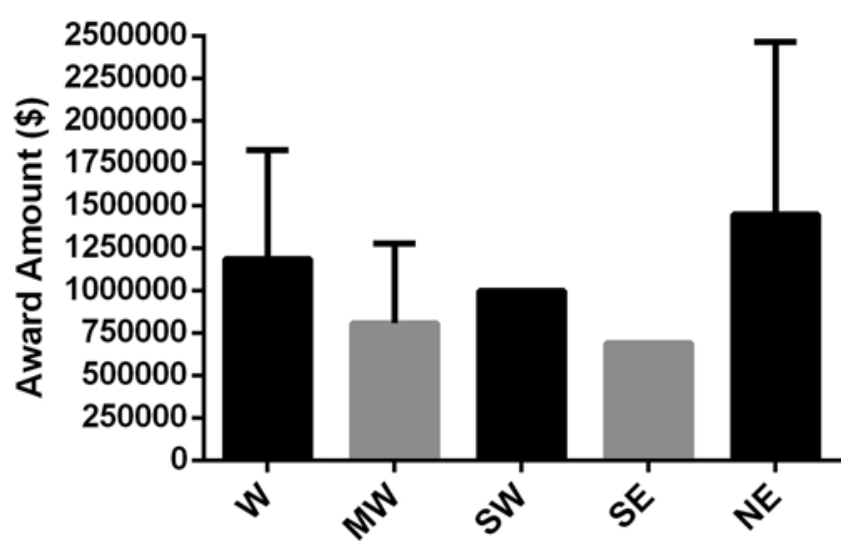

FIG. 4. Amount awarded to plaintiffs by US region, adjusted for inflation as of April 2020. Of note, the award amount for one settlement case was undisclosed. $\$=$ US\$; MW = Midwest; NE = Northeast; SE = Southeast; SW $=$ Southwest $; \mathrm{W}=$ West .

the true financial toll on spine surgery is largely unknown given that $85 \%$ of cases are dismissed or settled out of court, with undisclosed amounts. ${ }^{14}$ Likewise, substantial time is spent and costs, including legal and administrative, are incurred before judgment, as noted above.

\section{Frequency of Misplaced Pedicle and Lateral Mass Screws in Spine Surgery}

Spinal fusion procedures are increasingly performed each year, with Deyo et al. reporting that the number of Medicare patients who underwent a complex lumbar spine fusion for spinal stenosis increased 15-fold, from 1.3 persons per 100,000 Medicare persons in 2002 to 19.9 in $2007 .{ }^{31}$ Similarly, a study by Rajaee et al. demonstrated that the number of hospital discharges for spinal fusion increased 2.4 times (137\%) from 174,223 to 413,171 (p < 0.001 ) between 1998 and $2008 .^{32}$ The true frequency of malpositioned pedicle and lateral mass screws is likely underestimated in spine surgery given the fact that the majority of misplaced screws, as well as the potential complications related to them, are not reported in practice and may be clinically silent. Nevertheless, research has shown that screws are misplaced in approximately $14 \%-$ $55 \%$ of cases using the standard techniques (freehand and 2D fluoroscopic guidance) employed by most spine surgeons, ${ }^{21,33}$ resulting in injury in approximately $1 \%-8 \%$ of cases. ${ }^{21}$ In addition to the avoidable procedural risk to the patient, each misplaced screw carries the threat of future litigation, as reported above.

\section{Strategies to Improve the Accuracy of Screw Placement in Spine Surgery}

Many technological advances have been made over the past several decades in an effort to improve the accuracy of screw placement in spine surgery. ${ }^{34-36}$ For example, 3D fluoroscopy-based image guidance has been shown to decrease the pedicle breach rate in several studies compared to the rate with 2D fluoroscopic guidance or the freehand technique, particularly in deformity and revision surgeries. ${ }^{21,34,36,37} \mathrm{CT}$ guidance or intraoperative confirmation 
TABLE 3. Award information for 1995-2019

\begin{tabular}{|c|c|c|c|}
\hline Characteristic & $\begin{array}{l}\text { Plaintiff } \\
\text { Awarded }\end{array}$ & $\begin{array}{c}\text { Defendant } \\
\text { Awarded }\end{array}$ & $\mathrm{p}$ Value \\
\hline No. of cases & 21 & 47 & \\
\hline $\begin{array}{l}\text { Verdict year } \\
\text { range, no. (\%) }\end{array}$ & & & 0.112 \\
\hline 1995-1999 & $2(9.5)$ & $5(10.6)$ & \\
\hline 2000-2004 & $3(14.3)$ & $4(8.5)$ & \\
\hline 2005-2009 & $8(38.1)$ & $10(21.3)$ & \\
\hline 2010-2014 & $4(19.0)$ & $13(27.7)$ & \\
\hline 2015-2019 & $3(14.3)$ & $13(27.7)$ & \\
\hline Unknown & $1(4.8)$ & $2(4.3)$ & \\
\hline $\begin{array}{l}\text { Award type, } \\
\text { no. (\%) }\end{array}$ & & & NA \\
\hline Trial verdict & $13(61.9)$ & $47(100)$ & \\
\hline Settlement & $7(33.3)$ & NA & \\
\hline Arbitration & $1(4.8)$ & NA & \\
\hline $\begin{array}{l}\text { Median time to } \\
\text { case closure in } \\
\text { mos (IQR) }\end{array}$ & $56.3(35.2-67.2)$ & $61.5(51.4-77.2)$ & 0.117 \\
\hline $\begin{array}{l}\text { Mean nominal } \\
\text { award in US\$ }\end{array}$ & & & NA \\
\hline Trial verdict & $\$ 1,140,473 \pm \$ 841,683$ & NA & \\
\hline $\begin{array}{l}\text { Settlement/ } \\
\text { arbitration }\end{array}$ & $\$ 788,533 \pm \$ 306,186$ & NA & \\
\hline All cases & $\$ 1,031,625 \pm \$ 728,361$ & NA & \\
\hline $\begin{array}{l}\text { Mean inflation- } \\
\text { adjusted award } \\
\text { in US\$ }\end{array}$ & & & NA \\
\hline Trial verdict & $\$ 1,330,201 \pm \$ 882,023$ & NA & \\
\hline $\begin{array}{l}\text { Settlement/ } \\
\text { arbitration }\end{array}$ & $\$ 970,832 \pm \$ 381,619$ & NA & \\
\hline All cases & $\$ 1,204,422 \pm \$ 753,832$ & NA & \\
\hline
\end{tabular}

NA = not applicable.

has also been shown to further improve the accuracy of pedicle screw placement, ${ }^{36-38}$ with reported accuracy rates of $89 \%-100 \%$ reported in the literature, depending on the authors' breach criteria. ${ }^{35}$ However, it is important to note that the use of this technology is often accompanied by a lower threshold for intraoperative screw revision, sometimes leading to higher rates of replaced screws. ${ }^{33}$ Arguably, these improved trajectories may avoid iatrogenic neurological deficits due to prolonged nerve root compression or even improve the stability of the construct; $;^{34,37}$ however, prospective studies of long-term outcomes and rates of revision surgery remain sparse in the literature. Recently, robot-assisted pedicle screw implantation has been increasingly utilized at large-volume academic centers. In their meta-analysis of nine randomized controlled trials, $\mathrm{Li}$ et al. concluded that the robot-assisted technique was significantly more accurate than the traditional freehand technique. ${ }^{39}$ Despite the learning curve and initial cost of obtaining technologies such as 3D fluoroscopic devices, intraoperative $\mathrm{CT}$, or robotic navigational systems, the rou- tine use of these technologies for intraoperative imaging confirmation and potential revision of misplaced screws may help spine surgeons avoid inadvertent iatrogenic morbidity for their patients and potential litigation.

Importantly, these advanced technologies are not always readily available or the standard of care and cannot supplant a thorough understanding of operative anatomy, a high-quality surgical technique, and general complication-avoidance measures. Likewise, research shows that breaches still occur when these tools are used, ${ }^{33,40}$ and some studies did not find a difference in pedicle breach rates compared to those with traditional fluoroscopic and freehand techniques. ${ }^{33}$ Ultimately, misplaced instrumentation is a risk of any spinal fusion surgery, and a thorough discussion of these risks, as well as the alternative management options, is essential to maintain high-quality patient care and to avoid litigation.

\section{Study Limitations and Future Directions}

Several limitations should be carefully considered when interpreting our results. First, this is a retrospective analysis of cases obtained from the web-based Westlaw Edge legal research database. While reported to be one of the best legal research resources available and utilized in several previous studies, $7,14,16,23,24$ available court documents and clinical/operative details are highly variable and greatly limited among case files. Likewise, cases are uploaded on a voluntary basis by state and federal judges and courts, which may lead to selection bias. Thus, we are unable to comment on whether all misplaced screws, particularly when asymptomatic, should be revised in an effort to prevent litigation. This decision must be made on a case-by-case basis at the surgeon's and patient's discretion after a thorough discussion of the associated risks and benefits of revision surgery.

Moreover, local court rulings are not included in the Westlaw Edge database; however, this is unlikely to present meaningful bias given that malpractice claims are generally filed in state courts. In addition, studies have shown that over $85 \%$ of malpractice claims are either dismissed or settled out of court,,${ }^{14}$ which likely results in a high degree of underreporting. However, this is the first study to evaluate the direct medicolegal impact of misplaced pedicle and lateral mass screws on spine surgery in the US and presents important information that may support the routine use of intraoperative imaging confirmation (via 3D fluoroscopy or intraoperative CT) and/or navigated screw placement (either computer- or robot-assisted) as a potential method to decrease the risk of future litigation during spinal fusion procedures. Ultimately, additional prospective, multiinstitutional large-volume studies are needed to validate these findings, and future studies should evaluate the long-term impact on the routine use of intraoperative imaging confirmation and/or computer- or robot-assisted navigation on the frequency and success of malpractice claims related to misplaced pedicle and lateral mass screws.

\section{Conclusions}

Misplaced pedicle and lateral mass screws result in a considerable risk of malpractice litigation against spine 
surgeons. While the majority of verdicts are found in favor of the defendant (surgeon), over $30 \%$ of cases in this study were found in favor of the plaintiff (patient), resulting in average inflation-adjusted payouts of over $\$ 1.2$ million per claim over the past 25 years. In addition, the median time to judgment is substantial, particularly for defendant verdicts, spanning over 4.5 years from the time of surgery. Thus, meaningful efforts to limit the rate of misplaced pedicle and lateral mass screws, such as the routine use of intraoperative imaging confirmation and/or computer- or robot-assisted navigation, should be carefully considered.

\section{Acknowledgments}

Dr. Goodwin has received grants from the Burroughs Wellcome Fund, North Carolina Spine Society, and Robert Wood Johnson Harold Amos Medical Faculty Development Program and the NIH/NINDS K12 NRCDP Physician Scientist Award. Dr. Shaffrey has received grants from the NIH and Department of Defense.

\section{References}

1. Nahed BV, Babu MA, Smith TR, Heary RF. Malpractice liability and defensive medicine: a national survey of neurosurgeons. PLoS One. 2012;7(6):e39237.

2. Studdert DM, Mello MM, Sage WM, et al. Defensive medicine among high-risk specialist physicians in a volatile malpractice environment. JAMA. 2005;293(21):2609-2617.

3. Segal J. Defensive medicine: a culprit in spiking healthcare costs. Med Econ. 2012;89(10):70-71.

4. Sethi MK, Obremskey WT, Natividad H, et al. Incidence and costs of defensive medicine among orthopedic surgeons in the United States: a national survey study. Am J Orthop. 2012;41(2):69-73.

5. Din RS, Yan SC, Cote DJ, et al. Defensive medicine in U.S spine neurosurgery. Spine (Phila Pa 1976). 2017;42(3):177-185.

6. Balch CM, Oreskovich MR, Dyrbye LN, et al. Personal consequences of malpractice lawsuits on American surgeons. $J$ Am Coll Surg. 2011;213(5):657-667.

7. Makhni MC, Park PJ, Jimenez J, et al. The medicolegal landscape of spine surgery: how do surgeons fare? Spine J. 2018; 18(2):209-215.

8. Rothberg MB, Class J, Bishop TF, et al. The cost of defensive medicine on 3 hospital medicine services. JAMA Intern Med. 2014;174(11):1867-1868.

9. Smith TR, Hulou MM, Yan SC, et al. Defensive medicine in neurosurgery: the Canadian experience. J Neurosurg. 2016; 124(5):1524-1530.

10. Elsamadicy AA, Sergesketter AR, Frakes MD, Lad SP. Review of neurosurgery medical professional liability claims in the United States. Neurosurgery. 2018;83(5):997-1006.

11. Mukherjee S, Pringle C, Crocker M. A nine-year review of medicolegal claims in neurosurgery. Ann R Coll Surg Engl. 2014;96(4):266-270.

12. Jena AB, Seabury S, Lakdawalla D, Chandra A. Malpractice risk according to physician specialty. N Engl J Med. 2011; 365(7):629-636.

13. Rovit RL, Simon AS, Drew J, et al. Neurosurgical experience with malpractice litigation: an analysis of closed claims against neurosurgeons in New York State, 1999 through 2003. J Neurosurg. 2007;106(6):1108-1114.

14. Agarwal N, Gupta R, Agarwal P, et al. Descriptive analysis of state and federal spine surgery malpractice litigation in the United States. Spine (Phila Pa 1976). 2018;43(14):984-990.

15. Daniels AH, Ruttiman R, Eltorai AEM, et al. Malpractice litigation following spine surgery. J Neurosurg Spine. 2017; 27(4):470-475.
16. Rynecki ND, Coban D, Gantz O, et al. Medical malpractice in orthopedic surgery: a Westlaw-based demographic analysis. Orthopedics. 2018;41(5):e615-e620.

17. Ahmadi SA, Sadat H, Scheufler KM, et al. Malpractice claims in spine surgery in Germany: a 5-year analysis. Spine J. 2019;19(7):1221-1231.

18. Seabury SA, Chandra A, Lakdawalla DN, Jena AB. On average, physicians spend nearly 11 percent of their 40 -year careers with an open, unresolved malpractice claim. Health Aff (Millwood). 2013;32(1):111-119.

19. Todd NV. Insuring spinal neurosurgery. Br J Neurosurg. 2017;31(3):287-288.

20. Quraishi NA, Hammett TC, Todd DB, et al. Malpractice litigation and the spine: the NHS perspective on 235 successful claims in England. Eur Spine J. 2012;21(suppl 2):S196-S199.

21. Nottmeier EW, Seemer W, Young PM. Placement of thoracolumbar pedicle screws using three-dimensional image guidance: experience in a large patient cohort. J Neurosurg Spine. 2009;10(1):33-39.

22. Epstein NE. It is easier to confuse a jury than convince a judge: the crisis in medical malpractice. Spine (Phila Pa 1976). 2002;27(22):2425-2430.

23. Svider PF, Husain Q, Kovalerchik O, et al. Determining legal responsibility in otolaryngology: a review of 44 trials since 2008. Am J Otolaryngol. 2013;34(6):699-705.

24. Svider PF, Kovalerchik O, Mauro AC, et al. Legal liability in iatrogenic orbital injury. Laryngoscope. 2013;123(9):2099_ 2103.

25. Guillain A, Moncany AH, Hamel O, et al. Spine neurosurgeons facing the judicialization of their profession: disenchantment and alteration of daily practice-a qualitative study. Acta Neurochir (Wien). 2020;162(6):1379-1387.

26. Fager CA. Malpractice issues in neurological surgery. Surg Neurol. 2006;65(4):416-421.

27. Epstein NE. What can spine surgeons do to improve patient care and avoid medical negligence suits? Surg Neurol Int. 2020;11:38.

28. Moffatt-Bruce SD, Ferdinand FD, Fann JI. Patient safety: disclosure of medical errors and risk mitigation. Ann Thorac Surg. 2016;102(2):358-362.

29. Taylor CL. Neurosurgical practice liability: relative risk by procedure type. Neurosurgery. 2014;75(6):609-613.

30. Epstein NE. A review of medicolegal malpractice suits involving cervical spine: what can we learn or change? J Spinal Disord Tech. 2011;24(1):15-19.

31. Deyo RA, Mirza SK, Martin BI. Error in trends, major medical complications, and charges associated with surgery for lumbar spinal stenosis in older adults. JAMA. 2011;306(10):1088.

32. Rajaee SS, Bae HW, Kanim LE, Delamarter RB. Spinal fusion in the United States: analysis of trends from 1998 to 2008. Spine (Phila Pa 1976). 2012;37(1):67-76.

33. Bydon M, Xu R, Amin AG, et al. Safety and efficacy of pedicle screw placement using intraoperative computed tomography: consecutive series of 1148 pedicle screws. J Neurosurg Spine. 2014;21(3):320-328.

34. Mason A, Paulsen R, Babuska JM, et al. The accuracy of pedicle screw placement using intraoperative image guidance systems. J Neurosurg Spine. 2014;20(2):196-203.

35. Rajasekaran S, Bhushan M, Aiyer S, et al. Accuracy of pedicle screw insertion by $\mathrm{AIRO}^{\circledR}$ intraoperative $\mathrm{CT}$ in complex spinal deformity assessed by a new classification based on technical complexity of screw insertion. Eur Spine J. 2018; 27(9):2339-2347.

36. Nayar G, Blizzard DJ, Wang TY, et al. Pedicle screw placement accuracy using ultra-low radiation imaging with image enhancement versus conventional fluoroscopy in minimally invasive transforaminal lumbar interbody fusion: an internally randomized controlled trial. J Neurosurg Spine. 2018; 28(2):186-193. 
37. Scarone P, Vincenzo G, Distefano D, et al. Use of the Airo mobile intraoperative CT system versus the O-arm for transpedicular screw fixation in the thoracic and lumbar spine: a retrospective cohort study of 263 patients. J Neurosurg Spine. 2018;29(4):397-406.

38. Hecht N, Kamphuis M, Czabanka M, et al. Accuracy and workflow of navigated spinal instrumentation with the mobile AIRO $^{\circledR}$ CT scanner. Eur Spine J. 2016;25(3):716-723.

39. Li HM, Zhang RJ, Shen CL. Accuracy of pedicle screw placement and clinical outcomes of robot-assisted technique versus conventional freehand technique in spine surgery from nine randomized controlled trials: a meta-analysis. Spine (Phila Pa 1976). 2020;45(2):E111-E119.

40. Schatlo B, Molliqaj G, Cuvinciuc V, et al. Safety and accuracy of robot-assisted versus fluoroscopy-guided pedicle screw insertion for degenerative diseases of the lumbar spine: a matched cohort comparison. J Neurosurg Spine. 2014;20(6): 636-643.

\section{Disclosures}

Dr. Karikari is a consultant for NuVasive, Globus, Johnson \& Johnson, and DePuy and receives a spine fellowship fund from NuVasive. Dr. Shaffrey holds patents with, receives royalties from, and is a consultant for Medtronic, NuVasive, and Zimmer Biomet; is a stockholder in NuVasive; is a consultant for K2M, Stryker, SI
Bone, and In Vivo; and has received grants from the ISSG, DePuy Synthes, and AO Spine. Dr. Abd-El-Barr is a consultant for Spineology. Dr. K. D. Than is a consultant for Bioventus and receives honoraria from DJO and LifeNet Health.

\section{Author Contributions}

Conception and design: Sankey, KD Than. Acquisition of data: Sankey. Analysis and interpretation of data: Sankey, TT Than. Drafting the article: Sankey. Critically revising the article: all authors. Reviewed submitted version of manuscript: all authors. Statistical analysis: Sankey. Administrative/technical/material support: Mehta, Wang, KD Than. Study supervision: Goodwin, Karikari, Shaffrey, Abd-El-Barr, KD Than.

\section{Correspondence}

Eric W. Sankey: Duke University Medical Center, Durham, NC. eric.sankey@duke.edu. 